\title{
EFEITO DA UTILIZAÇÃO DE MANANOLIGOSSACARÍDEOS (MOS) E DE ÁCIDOS ORGÂNICOS ASSOCIADOS À MOS, COM E SEM ANTIBIÓTICOS, NA DIETA DE POEDEIRAS PRODUTORAS DE OVOS AVERMELHADOS
}

\author{
Carmen Lucia Garcez Ribeiro, ${ }^{1}$ Fernando Rutz, ${ }^{2}$ Paulo Roberto Dallmann, ${ }^{3}$ Niedi Franz Zauk, ${ }^{3}$ Marta \\ Helena Dias da Silveira, ${ }^{3}$ Rita de Albernaz Silva Goncalves, ${ }^{3}$ Marcos Antonio Anciuti ${ }^{4}$ e Patricia Rossi ${ }^{3}$ \\ 1. Departamento de Clinicas Veterinárias, área de Análises e Bioquímica Clinica, Nutrição Animal, UFPel. E-mail: caluribeiro@yahoo.com.br \\ 2. Professor do Departamento de Zootecnia, Faculdade de Agronomia Eliseu Maciel, UFPel \\ 3. Aluno do Programa de Pós-Graduação em Zootecnia, UFPel \\ 4. Professor do Conjunto Agrotécnico Visconde da Graça, CAVG.
}

\section{RESUMO}

O presente estudo teve como objetivo comparar o desempenho de poedeiras comerciais da linhagem Isa Brown com idade entre 32 e 52 semanas, alimentadas com dieta à base de milho e farelo de soja. Foram alojadas 240 poedeiras, em gaiolas individuais, divididas ao acaso em seis tratamentos, com quarenta repetições cada um. Ofereceram-se água e ração ad libitum. Constituíram-se os seguintes tratamentos: $\mathrm{T} 1$ - controle (dieta basal=DB), T2 - DB + antibiótico, $\mathrm{T} 3-\mathrm{DB}+$ mananoligossacarídeos (MOS) $(0,05 \%), \mathrm{T} 4-\mathrm{DB}+$ antibiótico + MOS, T5 - DB + ácidos orgânicos/MOS (AOM) $(0,1 \%)$ e $\mathrm{T} 6-\mathrm{DB}+$ antibiótico + AOM. Analisaram-se as seguintes variáveis: peso corporal médio das aves, consumo médio diário de ração, pro- dução média de ovos, peso médio do ovo, média da massa de ovo, conversão alimentar média por dúzia de ovo, conversão alimentar média/massa de ovo, coloração da gema, altura média do albúmen, média da unidade Haugh, gravidade específica média, percentagem média de casca, tempo de armazenamento. Submeteram-se os dados a ANOVA e, quando o teste F foi significativo, compararam-se as médias através de contrastes ortogonais duas a duas pelo teste de Tukey a 5\% de probabilidade. Os resultados indicam que, quando recebem AO ou MOS sem adição de antibiótico, as aves apresentam consumo médio diário de ração significativamente menor, sem alterar seu desempenho.

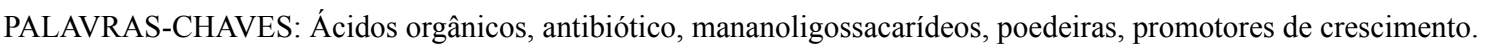

\section{EFFECT OF MANNANOLIGOSSACHARIDES (MOS) AND ORGANIC ACID/MOS (OAM) ALONE OR IN COMBINATION WITH ANTIBIOTICS IN BROWN-EGG LAYING HENS DIETS}

The present study aimed to compare the productive performance of Isa Brown -egg laying hens (32 to 52 weeks of age) fed a corn-soybean meal diet. The birds were randomly allocated into individual cages ( 40 cages/treatment) in a total of 240 animals. Feed and water were provided ad libitum. Treatments consisted of: T1- control (basal diet=BD); T2- D + antibiotic; T3- BD + mannanoligosaccharide (MOS) (0.05\%); T4- BD + antibiotic + MOS; T5- BD + organic acid/MOS (OAM) (0.1\%) and T6- BD + antibiotic
+ OAM. Body weight, egg production, egg weight, egg mass, feed conversion/dozen eggs and per egg mass, internal quality of eggs (egg yolk color, albumen height, Haugh units), eggs external quality (specific gravity, egg shell percentage) and time of storage were not affected by dietary treatments. The data were subjected to ANOVA and the means were compared by Tukey test. Results indicated that birds fed OAM and MOS without antibiotic had lowest feed consumption, without altering laying performance.

KEYWORDS: Antibiotic, growth promoters, laying hens, mannanoligosaccharide, organic acids. 


\section{INTRODUÇÃO}

Nos últimos quarenta anos, os antibióticos vêm sendo usados para melhorar o desempenho animal. São oferecidos durante o período de recria, para impedir o desenvolvimento de patógenos, manter a saúde e melhorar a qualidade da carne (PARKS et al., 2001).

A utilização de antibióticos promotores de crescimento pertencentes aos mesmos grupos de drogas empregadas na terapêutica animal e humana vem despertando a atenção das autoridades governamentais envolvidas com a saúde pública (EDENS, 2003).

Os antibióticos têm sido alvo de exame minucioso, dado o potencial desenvolvimento de bactérias patogênicas resistentes aos antibióticos na espécie humana, decorrente de uma utilização prolongada (FERKET et al., 2002).

Patógenos causadores de enfermidades têm preocupado a indústria avícola, em virtude da perda de produtividade, do aumento da mortalidade e da contaminação de produtos avícolas destinados ao consumo humano (PATTERSON \& BURKOLDER, 2003). Para atender a um mercado consumidor sensibilizado com a situação e em franca ascensão, tem-se estudado alternativas para a retirada dos antibióticos (promotores de crescimento) sem causar redução na produtividade e aumento no custo de produção. Normalmente, a retirada dos antibióticos promotores de crescimento de uma dieta acarreta aumentos no custo de produção, decorrente de uma piora na conversão alimentar (HRUBY, 2005). Essas alternativas devem considerar que os produtos substitutivos precisam ser baratos, eficientes e de fácil aplicação (VIOLA, 2006).

Dentre os controladores da carga microbiana no trato digestório e promotores de melhoria da morfologia intestinal, encontram-se os ácidos orgânicos (ácido propiônico e ácido fórmico) e os mananoligossacarídeos, demonstrando bons resultados na produção de aves. Trata-se de alternativas testadas extensivamente em frangos de corte, porém em menor escala em poedeiras.

O objetivo deste trabalho foi comparar o desempenho produtivo de poedeiras comerciais produtoras de ovos de cor avermelhada alimentadas com dietas contendo mananoligossacarídeos (MOS), ácidos orgânicos (ácido propiônico e ácido fórmico) e antibiótico em associação ou isolado.

\section{MATERIAL E MÉTODOS}

No aviário experimental do Departamento de Zootecnia da FAEM/UFPel, foram alojadas, em gaiolas individuais, medindo $0,25 \mathrm{~m}$ de largura $\mathrm{X} 0,35 \mathrm{~m}$ de profundidade $\mathrm{X} 0,40$ de altura, trezentas poedeiras comerciais semipesadas da linhagem Isa Brown, com trinta semanas de idade. Após uma adaptação de duas semanas, selecionaram-se 240 dessas aves, por meio de avaliação da condição produtiva consoante ficha de postura, sinais característicos de uma poedeira em produção (ENGLERT, 1998) e variação de peso corporal entre 1.700 e $2.400 \mathrm{~g}$.

Utilizaram-se quarenta poedeiras por tratamento, sendo cada ave considerada uma repetição, exceto para consumo médio diário. Cada grupo de quatro aves foi considerado uma unidade experimental.

Durante o período experimental, impôs-se um fotoperíodo de dezessete horas de luz ao dia. Ao final de cada ciclo de 28 dias, durante quatro períodos consecutivos, foram avaliados o consumo de ração, a qualidade interna e externa dos ovos, o ganho de peso, e coletados os ovos para avaliação do tempo de prateleira. Registrou-se a produção de ovos em planilhas, diariamente pela manhã, após o arraçoamento, e no início da tarde no momento da coleta dos ovos produzidos no dia. Nos três últimos dias de cada ciclo, os ovos foram coletados, identificados, pesados individualmente e medida a sua gravidade específica $(1,074$ até 1,100$)$. Nos ovos do último dia, avaliaram-se a coloração da gema pelo leque de Roche, o percentagem de casca e a Unidade Haugh. A utilização de antibiótico, MOS e ácidos orgânicos favorece a saúde intestinal, pois permite a absorção de nutrientes, propicionando melhor coloração da gema e qualidade de casca.

Os ovos produzidos no dia anterior ao dia das avaliações referentes ao final de cada ciclo foram conservados à temperatura ambiente, para avaliação do tempo de armazenamento. A cada dois dias eram quebrados, ao acaso, três ovos por tratamento, totalizando dez quebras de dezoito ovos em cada ciclo. Por ocasião da última quebra do ciclo, os ovos estavam com vinte dias de armazenamento. No momento da quebra, mediu-se a altura do albúmen, para posterior determinação da unidade Haugh e verificação da cor da gema. 
A composição e os níveis nutricionais da dieta básica usada em todos os tratamentos, para as diferentes fases de postura, são apresentados na Tabela 1.

TABELA 1. Composição percentual e níveis nutricionais das dietas experimentais básicas

\begin{tabular}{lcc}
\hline \multicolumn{1}{c}{ Ingredientes } & Postura I & Postura II \\
\hline Milho & 63,27 & 64,25 \\
Farelo de soja & 25,20 & 22,70 \\
Farelo de trigo & - & 1,00 \\
Fosfato bicálcico & 1,50 & 1,41 \\
Farinha de ostra grossa & 9,30 & 9,90 \\
Sal & 0,33 & 0,34 \\
Suplemento vitamínico, aminoacídi- & 0,40 & 0,40 \\
co e mineral ${ }^{1}$ & 100,00 & 100,00 \\
Total (kg) & 0,56 & 0,54 \\
Preço (R $\$ / k g)$ & & \\
\hline Níveis nutricionais & $2.731,06$ & $2.720,00$ \\
\hline Energia metabolizável (kcal/kg) & 16,70 & 15,80 \\
Proteína bruta (\%) & 3,50 & 3,50 \\
Cálcio (\%) & 0,32 & 0,32 \\
Fósforo disponível (\%) & 2,71 & 2,75 \\
Extrato etéreo (\%) & 2,94 & 2,89 \\
Fibra bruta (\%) & 1,93 & 1,63 \\
Ácido linoleico (\%) & 0,18 & 0,18 \\
Sódio total (\%) & & \\
\hline
\end{tabular}

${ }^{1}$ Nível de garantia por quilo de produto: vitaminas A 2.500000 UI, $\mathrm{D}_{3}$ 500000 UI, E $1750 \mathrm{mg}$, K $375 \mathrm{mg}, \mathrm{B}_{1} 400 \mathrm{mg}, \mathrm{B}_{2} 1100 \mathrm{mg}, \mathrm{B}_{6} 750 \mathrm{mg}, \mathrm{B}_{12}$ $3000 \mathrm{mg}$, ácido pantotênico $2.500 \mathrm{mg}$, ácido fólico $175 \mathrm{mg}$, niacina $6.500 \mathrm{mg}$ e metionina 250g; minerais: Mn $17500 \mathrm{mg}$, Zn 12500mg, Cu 2500mg, I $90 \mathrm{mg}$ e Se $76 \mathrm{mg}$.

As aves foram alimentadas com uma dieta composta principalmente por milho, farelo de soja, sendo $\mathrm{o}$ arraçoamento realizado diariamente às oito horas da manhã, em comedouros individuais, em porções de aproximadamente $115 \mathrm{~g} /$ ave/dia de ração, com reposição quando necessária, garantindo o consumo ad libitum.

As aves receberam dieta postura I até 35 semanas de idade (Tabela 1), e da $36^{\text {a }}$ até o final do experimento, postura II. Quando da ocorrência de mortalidade, as sobras de ração foram coletadas com posterior pesagem. Disponibilizou-se água em bebedouros tipo calha, também à vontade.

$\mathrm{O}$ experimento foi constituído de seis tratamentos: $\mathrm{T} 1$ - controle (dieta basal=DB), T2 - DB+ antibiótico $^{1}, \mathrm{~T} 3-\mathrm{DB}+$ mananoligossacarídeos $(\mathrm{MOS})^{2}$ $(0,05 \%), \mathrm{T} 4-\mathrm{DB}+$ antibiótico $+\mathrm{MOS}, \mathrm{T} 5-\mathrm{DB}+$ ácidos orgânicos/MOS $(\mathrm{AOM})^{3}(0,1 \%)$ e T6 - DB + antibiótico + AOM.

Empregou-se o delineamento experimental inteiramente ao acaso, com seis tratamentos, quarenta aves por tratamento, sendo cada ave considerada uma unidade experimental. Foram analisados os seguintes contrastes: C 1 - efeito antibiótico, C 2 - efeito MOS, C 3 - efeito antibiótico + MOS, C 4 - Efeito AOM, C 5 - efeito antibiótico + AOM.

Estudaram-se as variáveis: peso corporal médio das aves, consumo médio diário de ração, produção média de ovos, peso médio do ovo, média da massa de ovo, conversão alimentar média por dúzia de ovo, conversão alimentar média por massa de ovo, coloração da gema, altura média do albúmen, média da unidade Haugh, gravidade específica média, percentagem média de casca e tempo de armazenamento dos ovos.

\section{Modelo estatístico}

Yij $=m+$ ti + eij, em que: $Y i j=$ valor observado na parcela; $\mathrm{m}=$ média dos tratamentos; $\mathrm{t} i=$ efeito dos tratamentos i aplicado na parcela; eij = erro experimental.

Submeteram-se os dados à ANOVA e, quando o teste $\mathrm{F}$ foi significativo, compararam-se as médias através de contrastes ortogonais e pelo teste de Tukey a $5 \%$ de probabilidade.

\section{RESULTADOS E DISCUSSÃO}

Submeteram-se os valores médios referentes ao consumo diário de ração à análise da variância e verificou-se que, ao final do período experimental, ocorreram diferenças significativas (Tabela 2). As aves que apresentaram os menores consumos foram aquelas que receberam o tratamento contendo ácido fórmico e propiônico associados à mananoligossacarídeos, seguidos daquelas que receberam mananoligossacarídeos na dieta. Essas reduções no consumo, em relação aos demais tratamentos, se devem ao efeito inibidor sobre

1 Bacitracina de zinco.

$2 \operatorname{BioMos}^{\circledR 2}$ (Alltech Inc.) Composição: Saccharomyces cerevisae, mananoligossacarídeos fosforilados $30 \% / \mathrm{kg}$.

3 Avi $\operatorname{Mos}^{\circledR 3}$ (Alltech Inc.) Composição: ácido fórmico $150 \mathrm{~g} / \mathrm{kg}$, ácido propiônico $150 \mathrm{~g} / \mathrm{kg}$, mananoligossacarídeo, farelo de trigo, vermiculita e Saccharomyces cerevisae. 
o desenvolvimento microbiano e à influência sobre a disponibilidade dos nutrientes atribuída aos ácidos orgânicos, o que, segundo GAMA et al. (2000), sustenta a sua aplicabilidade. Também em relação aos mananoligossacarídeos, FERKET et al. (2002) e FERKET (2004) relatam que esses aditivos reduzem a coloniza- ção intestinal por bactérias patogênicas, favorecendo, com isso, o crescimento de bactérias benéficas lácticas com consequente queda do $\mathrm{pH}$ do bolo intestinal. Isso impede a proliferação de bactérias de putrefação e a liberação de amônia, contribuindo para melhoria da integridade do epitélio intestinal.

TABELA 2. Consumo médio diário de ração durante o período experimental

\begin{tabular}{|c|c|c|c|c|c|}
\hline \multirow{2}{*}{ Tratamento } & \multicolumn{5}{|c|}{ Ciclos (28 dias) } \\
\hline & $1^{\mathrm{o}}$ & $2^{o}$ & $3^{\circ}$ & $4^{\circ}$ & Período \\
\hline Controle (DB) & $154,20_{\mathrm{c}}$ & $98,37_{\mathrm{a}}$ & $122,30_{b}$ & $137,70_{\mathrm{a}}$ & $128,10_{\mathrm{a}}$ \\
\hline DB + antibiótico & $153,90_{c}$ & $92,70_{b}$ & $119,40_{c}$ & $110,20_{c}$ & $119_{d}$ \\
\hline $\mathrm{DB}+\mathrm{MOS}$ & $157,60_{b}$ & $91,70_{b}$ & $124,80_{\mathrm{a}}$ & $93,70_{d}$ & $117_{\mathrm{e}}$ \\
\hline $\mathrm{DB}+$ antibiótico $+\mathrm{MOS}$ & $157_{b}$ & $99,60_{\mathrm{a}}$ & $118,90_{c}$ & $119,90_{b}$ & $123,90_{b}$ \\
\hline $\mathrm{DB}+\mathrm{AOM}$ & $150,50_{\mathrm{d}}$ & $93,10_{b}$ & $121,40_{b}$ & $87,70_{\mathrm{e}}$ & $113,30_{\mathrm{f}}$ \\
\hline $\mathrm{DB}+$ antibiótico $+\mathrm{AOM}$ & $160,50 \mathrm{a}$ & $97,00_{b}$ & $116,80_{\mathrm{d}}$ & $110,50_{c}$ & $121_{c}$ \\
\hline $\mathrm{P}$ & 0,0001 & 0,0001 & 0,0001 & 0,0001 & 0,0001 \\
\hline $\mathrm{CV} \%$ & 2,08 & 2,09 & 2,20 & 2,06 & 1,75 \\
\hline
\end{tabular}

*Em cada coluna, médias seguidas da mesma letra não diferem entre si a 5\% de probabilidade pelo teste de Tukey, CV(coeficiente de variação).

Os resultados relativos ao consumo médio diário de ração concordam com os relatados por CELIK et al. (2003). Esses autores, em avaliação do efeito de um produto comercial à base de ácido fórmico, formiato de amônia, ácido propiônico e propionato de amônia em perus, encontraram pequeno efeito no ganho de peso com tendência a aumentá-lo e a diminuir o consumo de ração. Da mesma forma, os resultados obtidos durante o experimento concordam também com os de DO VALE et al. (2004), que, ao trabalharem com frangos de corte, testaram uma mistura de ácido fórmico $(70 \%)$ e propiônico $(30 \%)$, associação esta que determinou uma redução no consumo de ração, até 42 dias de idade, com $2 \%$ de inclusão dessa mistura.

Em contraposição, ZAGHINI et al. (2005), avaliando o efeito de MOS e micotoxina, não encontraram efeito aparente no consumo alimentar. Também GARCIA et al. (2000), usando ácido orgânico e antibiótico em dietas para frangos de corte, não encontraram efeito significativo em relação a essa variável. Já consumos semelhantes, em frangos de corte até 21 dias de idade, com dietas contendo antibiótico e MOS, foram relatados por GRIGOLETTI et al. (2002) e ALBINO et al. (2006), em trabalho com frangos até 42 dias de idade.
Consumos maiores foram observados por GARCIA et al. (1998), utilizando dietas iniciais para pintos de corte com grãos de sorgo úmidos, com ou sem incorporação de ácido acético e propiônico, a 1,8\%. Porém, ao utilizarem grãos de sorgo secos, encontraram consumos médios equivalentes em todas as dietas iniciais.

Aumento significativo no consumo alimentar foi relatado por DENLI et al. (2003), em trabalho com frangos de corte, utilizando dietas contendo antibiótico bem como uma mistura de ácidos orgânicos, e por FLEMMING (2005), utilizando tanto antibiótico quanto MOS.

Não houve efeito dos tratamentos, ao nível de $5 \%$, em relação ao peso corporal médio das poedeiras, à conversão alimentar média/dúzia de ovo e /massa de ovo, à produção diária de ovos por ave alojada, ao do peso médio do ovo e à percentagem média de casca (Tabela 3).

Os resultados referentes ao peso médio das poedeiras, encontrados ao final do experimento, são semelhantes aos reportados por ZAGHINI et al. (2005), utilizando MOS e micotoxina, bem como por STANLEY et al. (1999), com MOS em dietas contendo aflatoxinas, e DAMRON \& WILSON (1983), 
utilizando metileno dissalicilato de bacitracina (BMD). Da mesma forma, também com frangos de corte, GRIGOLETTI et al. (2002), utilizando antibióticos e levedura, WALDROUP et al. (2003), empregando antibiótico e Bio-Mos, GARCIA et al. (1998), usando ácidos orgânicos em dietas iniciais, e GARCIA et al. (2000) utilizando, além de ácidos orgânicos, antibióticos nas fases de terminação e total, não encontraram diferenças no ganho de peso. Melhora no ganho de peso de frangos foi verificada por MILES et al. (2006) com o uso de BMD ou virginiamicina (VM); por ALBINO et al. (2006), com taxas padrões de MOS combinado ou não com avilamicina, por FLEMMING (2005), pela ação de Bio-Mos ${ }^{\circledR}$ ou antibiótico, e por MILES et al. (2006), com BMD ou VM. O ganho de peso também foi influenciado positivamente em perus, como constatado por SIMS et al. (2004), trabalhando com BMD, MOS ou combinados.

TABELA 3. Peso corporal médio (g) (PCM), conversão alimentar média por dúzia (CAM/dz) e por massa de ovos (CAM/ms), produção diária de ovos (PDO), peso médio do ovo (g) ( PMO) e percentagem média de casca dos ovos (PMC) durante o período experimental

\begin{tabular}{lcccccc}
\hline \multirow{2}{*}{ Tratamento } & \multicolumn{5}{c}{ Ciclos (28 dias) } \\
\cline { 2 - 7 } Controle (DB) & PCM & CAM/dz & CAM/ms & PDO & PMO & PMC \\
DB + antibiótico & $1.927,58$ & 1,76 & 2,30 & 90,32 & 62,50 & 10,19 \\
DB + MOS & $1.824,72$ & 1,64 & 2,24 & 88,75 & 60,52 & 10,37 \\
DB + antibiótico + MOS & $1.900,71$ & 1,67 & 2,20 & 87,60 & 61,92 & 10,16 \\
DB + AOM & $1.851,55$ & 1,70 & 2,30 & 89,53 & 60,70 & 10,30 \\
DB + antibiótico + AOM & $1.874,69$ & 1,68 & 2,16 & 86,09 & 62,57 & 10,29 \\
P & $1.909,86$ & 1,70 & 2,24 & 88,37 & 61,57 & 10,25 \\
CV & ns & ns & ns & ns & $n s$ & $n$ \\
\hline
\end{tabular}

$\mathrm{CV} \%=$ coeficiente de variação; ns = não significativo.

DIBNER \& RICHARDS (2005) citam que o principal objetivo da utilização de antibióticos em rações é de melhorar a conversão alimentar, o que não foi constatado no presente experimento com nenhum dos aditivos usados.

A conversão alimentar em frangos de corte também não foi influenciada pelos tratamentos empregados por ALBINO et al. (2006), com MOS e avilamicina até 42 dias de idade, bem como por WALDROUP et al. (2003), testando Bio-Mos ${ }^{\circledR}$, e SMITH \& SANZ (1991), utilizando leveduras.

No entanto, melhora na conversão alimentar e nos pesos vivos foi encontrada por HULET (2007), em pavoas que receberam MOS; por SIMS et al. (2004), em perus, com resultados favoráveis ao MOS e melhor ainda quando em associação com BMD; por WALDROUP et al. (2003), em frangos de corte com o uso de antibióticos.

Como MOS atua para reduzir a carga intestinal de bactérias patogênicas, prevenindo assim uma resposta imune aguda contra estas (SPRING et al., 2000), e os ácidos orgânicos passam a ter uma ação antibacteriana particularmente contra bactérias Gramnegativas (OSTERMAN et al., 2005), por alterarem o $\mathrm{PH}$, haveria um melhor aproveitamento dos nutrientes que seriam eficientemente direcionados para a produção, o que poderia culminar numa maior produção de ovos. Equivalência nessa variável produtiva entre os tratamentos encontrada no presente experimento pode ser atribuída ao baixo nível de desafio e ao alojamento das aves em baterias, impedindo a reinfecção dessas poedeiras, por não oportunizar aos aditivos plenitude de ação. Como todos os tratamentos consistiam da mesma dieta basal, com variação apenas do aditivo, podese concluir que eles foram capazes de disponibilizar às poedeiras níveis energéticos similares, uma vez que o nível energético da dieta está diretamente relacionado com os índices de postura (LEESON, 1996).

Também ZAGHINI et al. (2005), em avaliação do efeito da inclusão de MOS e micotoxina, e STAN- 
LEY \& SEFTON (1999), mediante análise do uso aflatoxina e Bio-Mos ${ }^{\circledR}$ isolados ou combinados, não encontraram efeito na produção de ovos. SHASHIDHARA\& DEVEGOWDA(2003), em estudo também do efeito da suplementação de MOS em fêmeas Cobb, constataram que não houve influência na produção de ovos.

Efeito positivo na produção diária de ovos foi relatado por DAMRON \& WILSON (1983), com o uso de BMD, bem como por BERRY \& LUI (2000), STANLEY et al. (2000) e ainda por GAMA et al. (2000), com ácidos orgânicos.

A análise dos resultados da gravidade específica média (Tabela 4) mostra que não houve diferença significativa entre os tratamentos durante o período experimental.

Esses resultados indicam que o uso dos diferentes aditivos contribuiu de forma semelhante na disponibilidade dos nutrientes da dieta, dentre esses a proteína cujo teor, conforme LEESON (1996), é o principal responsável pela variação do tamanho do ovo. Inexistência de diferença relativa ao peso dos ovos foi também constatada por SMITH \& SANZ (1991), com a utilização de leveduras na ração de matrizes, e por GAMA et al. (2000), na suplementação de ácidos orgânicos a frangas Isa Brown de quatro meses de idade. Já ZAGHINI et al. (2005), avaliando MOS e micotoxina em poedeiras, observaram que houve decréscimo no peso dos ovos nos grupos alimentados com a dieta suplementada no final da segunda e terceira semana do experimento. Desse modo, o grupo MOS voltou a ter peso de ovo semelhante aos outros grupos depois de quatro semanas.

A gravidade específica estima a quantidade de casca depositada, o que tem relação com a sua resistência à quebra. Os pesos médios de casca encontrados no presente trabalho foram ligeiramente superiores aos limites considerados por CEULAR \& MORENO (1998), que mencionam que o peso da casca do ovo pode variar de $3,5 \mathrm{a} 6 \mathrm{~g}$.

ZAGHINI et al. (2005) mencionaram pesos de casca significativamente menores nas galinhas que receberam dietas com aflatoxina B1 comparadas com os do grupo MOS. Aumento da gravidade específica de ovos foi verificada por MARTINS (2005), usando diformiato de potássio.

TABELA 4. Cor da gema (CG), gravidade específica média (GEM) e média das unidades Haugh (MUH) dos ovos durante o período experimental

\begin{tabular}{llll}
\hline \multirow{2}{*}{ Tratamento } & \multicolumn{3}{c}{ Ciclos (28 dias) } \\
\cline { 2 - 4 } Controle (DB) & CG & GEM & 102,28 \\
DB + antibiótico & 8,97 & 1,098 & 103,57 \\
DB + MOS & 9,07 & 1,099 & 103,47 \\
DB + antibiótico + MOS & 9,17 & 1,098 & 103,09 \\
DB + AOM & 8,97 & 1,099 & 103,67 \\
T6 - DB + antibiótico + AOM & 9,07 & 1,099 & 102,17 \\
P & 9,15 & 1,098 & $\mathrm{~ns}$ \\
CV & ns & ns & 5,06 \\
\hline
\end{tabular}

$\mathrm{CV} \%=$ coeficiente de variação; ns = não significativo.

Os parâmetros de qualidade interna do ovo (coloração da gema, gravidade específica média, média da unidade Haugh) avaliados durante o período (Tabela 4) e média da unidade Haugh no tempo de armazenamento (Tabela 5) não sofreram influência dos tratamentos. $\mathrm{O}$ mesmo resultado também foi verificado por GAMA et al. (2000), em relação à média de unidades Haugh, testando uma mistura de ácidos orgânicos, e por ZAGHINI et al. (2005), em avaliação do efeito de tratamentos com a inclusão de MOS e micotoxina em poedeiras. Esses autores encontraram médias para todos os tratamentos, para índice Haugh (calculado em 
termos de unidade Haugh), de 62,34 $\pm 0,67, \square 13,34 \mathrm{e}, \quad \pm$ relacionando o MOS com provável aumento de para cor da gema (medida por cromômetro), de 17,71 porcentagem de proteína do albúmen.

TABELA 5. Média da unidade Haugh de ovos mantidos armazenados em condições ambientais

\begin{tabular}{|c|c|c|c|c|c|c|c|c|c|c|}
\hline \multirow[t]{2}{*}{ Tratamentos } & \multicolumn{10}{|c|}{ Dias de armazenamento } \\
\hline & 2 & 4 & 6 & 8 & 10 & 12 & 14 & 16 & 18 & 20 \\
\hline Controle (DB) & 98,23 & 104,58 & 102,27 & 99,34 & 98,35 & 99,53 & 93,50 & 94,65 & 92,88 & 86,04 \\
\hline DB + antibiótico & 98,42 & 106,28 & 103,19 & 98,65 & 101,94 & 98,34 & 96,63 & 93,94 & 95,89 & 92,41 \\
\hline $\mathrm{DB}+\mathrm{MOS}$ & 97,98 & 99,72 & 105,74 & 102,87 & 101,38 & 97,52 & 92,87 & 96,96 & 98,84 & 90,42 \\
\hline $\mathrm{DB}+$ antibiótico $+\mathrm{MOS}$ & 96,55 & 100,47 & 96,43 & 99,51 & 98,13 & 101,20 & 93,91 & 91,86 & 94,81 & 90,49 \\
\hline $\mathrm{DB}+\mathrm{AOM}$ & 96,04 & 104,33 & 104,28 & 100,77 & 98,45 & 99,54 & 98,41 & 96,28 & 97,57 & 95,49 \\
\hline $\mathrm{DB}+$ antibiótico $+\mathrm{AOM}$ & 98,99 & 105,90 & 101,64 & 99,66 & 96,88 & 98,26 & 99,54 & 95,95 & 96,25 & 93,97 \\
\hline $\mathrm{P}$ & ns & ns & Ns & ns & ns & ns & ns & Ns & ns & $\mathrm{ns}$ \\
\hline $\mathrm{CV} \%$ & 6,92 & 7,05 & 4,77 & 6,11 & 6,42 & 4,67 & 6,17 & 5,78 & 4,37 & 5,46 \\
\hline
\end{tabular}

$\mathrm{CV} \%=$ coeficiente de variação; $\mathrm{ns}=$ não significativo.

\section{CONCLUSÕES}

Os resultados obtidos no presente experimento demonstraram que tanto AOM como MOS podem ser usados em substituição aos antibióticos promotores de crescimento sem alterar o desempenho zootécnico de poedeiras. Os aditivos não aumentaram a produtividade de poedeiras produtoras de ovos avermelhados, bem como não influenciaram a qualidade dos ovos.

\section{REFERÊNCIAS}

ALBINO, L. F. T.; FERES, F. A.; DIONIZIO, M. A.; ROSTAGNO, H. S.; JÚNIOR, J. G. de V.; CARVALHO, D. C. D. E. O.; GOMES, P. C.; COSTA,C. H. R. Uso de prebióticos à base de mananoligossacarídeo em rações para frangos de corte. Revista Brasileira de Zootecnia, v. 35, n. 3, p. 742-749, 2006.

BERRY, W. D.; LUI, P. Egg production, egg shell quality and bone parameters in broiler breeder hens receiving Bio-Mos and eggshell 49. Poultry Science, v. 79, n. 1, p. 124, 2000. Disponível em: http:// www.poultryscience.org/spss00.pdf . Acesso em: 20 abril 2008.

ÇELIK, K.; ERBIL, E.; AHMET, U.; MUSTAFA, E. The using of organic acids in California turkey chicks and its effects on performance before pasturing. International Journal of Poultry Science, v. 2, n. 6, p. 446-448, 2003.

CEULAR, A.; MORENO, A. La qualidad de la cáscara del huevo (I). Avicultura Profesional, v. 16, n. 4, 1998.
DAMRON, B. L.; WILSON, H. R. Bacitracin methylene disalicylate in broiler breeder feeds. Britsh Poultry Science, v. 24, n. 4 , p. 455-62, 1983.

DENLI, M.; OKAN, F.; ÇELIK, K. Effect of dietary probiotic, organic acid and antibiotic supplementation to diets on broiler performance and carcass yield. Pakistan Journal of Nutrition, v. 2, n. 2, p. 89-91, 2003.

DIBNER, J. J.; RICHARDS, J. D. Antibiotic growth promoters in agriculture: history and mode of action. Poultry Science, v. 84 , p. 634-643, 2005.

DO VALE, M. M.; MENTEN, J. F. M.; MORAIS, S. C. D. de; BRAINER, M. M. de A. Mixture of formic and propionic acid as additives in broiler feeds. Scientia Agricola, v. 61, n. 4, p. 371375, July/Aug. 2004

EDENS, F. W. An alternative for antibiotics use in poultry: probiotics. Brazilian Journal of Poultry Science, v. 5, n. 2, p. 75-97, 2003.

ENGLERT, S. Avicultura: tudo sobre raças, manejo e alimentação. 7. ed. Guaíba: Livraria e Editora Agropecuária, 1998. 240 p.

FERKET, P. R. Alternatives to antibiotics in poultry production: responses, practical experience and recommendations. 2007. Disponível em: $<$ http://en.engormix.com/MA-poultry-industry/ articles/alternatives-antibiotics-poultry-production_405.htm.> Acesso em: 29 abril 2008.

FERKET, P. R.; PARKS, C. W.; GRIMES, J. L. Benefits of dietary antibiotic and mannanoligosaccharide supplementation for poultry. 
Proc Multi-State Poultry Meeting, May 14-16, 2002. Disponível em: <http://www.feedinfo.com/files/multi2002-ferket.pdf $>$ Acesso em: 29 abril 2008.

FLEMMING, J. S. Utilização de leveduras, probióticos e mananoligossacarídeos (MOS) na alimentação de frangos de corte. 2005, $111 \mathrm{f}$. Tese (Doutorado em Tecnologia de Alimentos) - Universidade Federal do Paraná, Curitiba, 2005. Disponível em: $<$ http://dspace.c3sl.ufpr.br/dspace/bitstream/1884/2344/1/Tese $\% 20$ -\%20Jos\%C3\%A9\%20Sidney\%20Flemming\%5B1\%5D.pdf > . Acesso em: 28 abril 2008.

GAMA, N. M. S. Q.; OLIVEIRA, M. B. C. de; SANTIN, E.; JUNIOR, Â. B. Ácidos orgânicos em rações de poedeiras comerciais. Ciência Rural, v. 30, n. 3, p. 499-502, 2000.

GARCIA, D. C.; MAIER, J. C.; ELIAS, M. C. Alimentação de pintos com grãos de sorgo tratados com ácidos orgânicos e armazenados convencionalmente. Revista Brasileira de Agrociências, v. 4, n. 1, p. 55-58, 1998.

GARCIA, R.G.; ARIKI, J.; MORAES, V.M.B.; KRONKA, S.N.; BORGES, S.A.; MURATA, L.S.; CAMPOS, V.A. Ação isolada ou combinada de ácidos orgânicos e promotor de crescimento em rações de frangos de corte. Revista Brasileira de Ciência Avícola, v. 2, n. 2, 2000. Disponível em: <http://www.scielo.br/ scielo.php?script $=$ sci_arttext\&pid=S1516-635X2000000200004 $>$ Acesso em: 20 abril 2008.

GRIGOLETTI, C; FRANCO, S.G.; FLEMMING, J.S.; FEDALTO, L.M.; BACILA, M. Saccharomyces cerevisae na alimentação de frangos de corte (Saccharomyces cerevisae in the broilers feeding). Archives of Veterinary Science, v. 7, n. 2, p. 151-157, 2002.

HRUBY, M. Las enzimas en el alimento y la betaína ayudan a reemplazar AGPs. Avicultura Profesional, v. 23, n. 5, 2005.

HULET, R. M. Comparación de las respuestas de oligosacáridos mananos y antibióticos: efectos sobre el rendimiento de la pava reproductora. Disponível em: $<$ http://www.engormix.com/comparacion_respuestas_oligosacaridos_mananos_articulo 170_AVG.htm> Acesso em: 20 ago. 2007.

LEESON, S. Programas de alimentación para ponedoras e broilers. In: CURSO DE ESPECIALIZACIÓN FEDNA, 12., Madrid, Espanha, p. 201-216, 1996. Disponível em:

$<$ http://www.etsia.upm.es/Fedna/capitulos/96capituloXI.pdf $>$ Acesso em: 14 abr. 2007.

MARTINS, P. E. Avaliação do diformiato de potássio sobre o desempenho produtivo e reprodutivo de matrizes de corte. 2005. 88 f. Dissertação (Mestrado em Zootecnia) - Universidade Federal de Santa Maria, Santa Maria. Disponível em: <http://w3.ufsm. br/ppgz/download/Dissertacoes2005/PatriciaEickMartins.pdf $>$ Acesso em: 11 abr. 2007.
MILES, R. D.; BUTCHER, G. D.; HENRY, P. R.; LITTELL, R, C. Effect of antibiotic growth promoters on broiler performance, intestinal growth parameters, and quantitative morphology. Poultry Science, v. 85, p. 476-485, 2006.

OSTERMANN, D. ; SANFELICE, A. M ; VIEIRA, S. L. ; VIOLA, E. S. Metabolismo e bases conceituais para a ação benéfica de ácidos orgânicos para frangos de corte. Ave World, v. 3, n. 15, p. 28-32, 2005.

PARKS, C. W.; GRIMES, J. L.; FERKET, P. R.; FAIRCHILD, A. S. The effect of mannanoligosaccharides, bambermycins, and virginiamycin on performance of large white male market turkeys. Poultry Science, v. 80, p. 718-723, 2001.

PATTERSON, J.A.; BURKHOLDER, K.M. Application of prebiotics and probiotics in poultry production. Poultry Science, v. 82, p. 627-631, 2003.

SHASHIDHARA, R. G.; DEVEGOWDA, G. Effect of dietary mannan oligosaccharide on broiler breeder production traits and immunity. Poultry Science, v. 82, p. 1319-1325, 2003.

SIMS, M. D.; DAWSON, K. A.; NEWMAN, ; K. E.; SPRING, P.; HOOGE, D. M. Effects of dietary mannan oligosaccharide, bacitracin methylene disalicylate, or both on the live performance and intestinal microbiology of turkeys. Poultry Science, v. 83, p. 1148-1154, 2004.

SMITH. M.; SANZ, M. Use of poultry slaughterhouse waste, meat meal and Mozyr yeast for breeding hens. Revista Cubana de Ciencia Avícola, v. 18, n. 3, p. 221-225, 1991.

SPRING, P.; WENK, C.; DAWSON, K. A.; NEWMAN, K. E. The effects of dietary mannanoligosaccharides on cecal parameters and the concentrations of enteric bacteria in the ceca of Salmonella-challenged broiler chicks. Poultry Science, v. 79, p. 205-211, 2000.

STANLEY, V. G.; SEFTON, A. E. Egg and serum cholesterol as influenced by mannan oligosaccharide and aflatoxin. In: SIM,I. S.; NAKAI, S.; GUENTER, W. (Ed.). Egg nutrition and biotechnology. Wallingford: UK: CABI Publishing, 1999. p. 441-443.

STANLEY, V. G.; BROWN, C.; SEFTON, T. Single and combined effects of dietary protease and mannanoligosaccharide on the performance of laying hens. Poultry Science, v. 79, n. 1, p. 62, 2000. (Abstr.).

VIOLA, E. S. Uso de acidificantes em dietas de frangos de corte: resíduos no trato digestivo e efeitos sobre o desempenho animal e morfologia intestinal. 2006. 196 f. Tese (Doutorado em Agronomia) - Universidade Federal do Rio Grande do Sul, Porto Alegre. Disponível em: <http://www.lume.ufrgs.br/handle/10183/7069> Acesso em: 10 abr. 2007. 
WALDROUP, P. W.; FRITTS C. A ; YAN, F.Utilization of BioMos ${ }^{\circledR}$ mannan oligosaccharide and Bioplex ${ }^{\circledR}$ Copper in broiler diets. International Journal of Poultry Science, v. 2, n. 1, p. 44-52, 2003.
ZAGHINI, A.; MARTELLI, G.; RONCADA, P.; SIMIOLI, M.; RIZZI, L. Mannanoligosaccharides and Aflatoxin B1 in feed for laying hens: effects on egg quality, Aflatoxins B1 and M1 residues in eggs, and Aflatoxin B1 levels in liver. Poultry Science, v. 84, p. $825-832,2005$.

Protocolado em: 22 jan. 2008. Aceito em: 24 fev. 2010. 